Br Heart J 1987;58:185-9

Editorial

\title{
Assessing the success of percutaneous transluminal coronary angioplasty
}

\author{
PATRICK D V BOURDILLON \\ From the Department of Medicine, Indiana University Medical School, and Krannert Institute of \\ Cardiology, Indianapolis, Indiana, USA
}

\section{The goals}

Evaluation of the success of a therapeutic procedure should be related to the technical and clinical goals set for that procedure. For percutaneous transluminal coronary angioplasty the goal set depends on the clinical circumstances. For stable angina pectoris it is the elimination of exertional ischaemia; however in an elderly patient or a patient with severe associated non-cardiac disease, in whom coronary artery bypass surgery would be too hazardous, the goal may be limited to reducing the severity of angina pectoris to acceptable levels. There may also be a secondary goal of reducing the risk of subsequent major cardiac events, such as acute myocardial infarctions or improving prognosis. The intention in unstable angina is also to eliminate ischaemia but in some cases prevention of an impending infarction and conversion of the symptoms from an unstable pattern to a stable pattern may be an acceptable therapeutic result. During an evolving acute myocardial infarction caused by coronary occlusion angioplasty may be used to open the artery and reduce the stenosis sufficiently to limit the extent of the myocardial infarction and preserve left ventricular function. Here it may not be advisable or desirable to attempt to dilate the artery to the extent that might be attempted in a patient with stable angina pectoris and single vessel disease. Similarly, when there is chronic total occlusion of a vessel, angioplasty can be used to achieve dilatation sufficient to permit anterograde flow in that artery before attempting dilatation of another artery. If the second artery becomes occluded at angioplasty, flow in collaterals from the first artery may avoid catastrophic haemodynamic collapse.

Requests for reprints to Dr Patrick D V Bourdillon, Indiana University Hospital, Room N562, 926 West Michigan Street, Indianapolis, IN 46223, USA.

\section{Measuring success}

An inherent criterion of success in all these situations is not to harm the patient. So procedures causing death or myocardial infarction or requiring emergency coronary artery bypass grafting because of acute occlusion or dissection are by definition unsuccessful. Apart from these major complications and the inability to cross and dilate the lesion at all, there are few cases in which an operator will view the procedure as "unsuccessful". Procedures which do not improve the degree of stenosis (perhaps because there is dissection) but where occlusion is not total and bypass is not required may belong to this category. Such patients would generally be considered for coronary bypass surgery, which is the normal, though not the exclusive, alternative treatment for angina pectoris in patients in whom angioplasty is attempted.

Whenever specific numerical angiographic criteria are used to define success, there is a reasonable natural tendency to classify as successful any procedure in which the above criteria for lack of success are not met. It may therefore be more realistic to define as successful, procedures that are not clearly failures, although there will be a subgroup of these "successful" procedures that could more accurately be classified as "partially successful". Perhaps the most relevant question is "did we do what we came to do?"

\section{Primary success}

Most published reports refer to the "primary success" of angioplasty rather than its "clinical success". Primary success is based on angiographic criteria and the technical goal is to reduce the angiographic stenosis to an acceptable level. This will vary with the clinical situation and the coronary anatomy. Unfortunately, such variability is difficult to handle statistically and investigators found it is more con- 
venient to use standard criteria. An early definition of primary success used in the landmark paper by Gruentzig and coworkers when they described the results in their first 32 patients was a $10 \%$ reduction in diameter stenosis or gradient. ${ }^{1}$ Since angiographers generally use diameter stenosis rather than area stenosis in referring to numerical degrees of stenosis this convention will be followed here. Subsequently Gruentzig and coworkers regarded a reduction in angiographic stenosis of $\geqslant 20 \%$ as indicative of primary success, ${ }^{2}$ although they also used reduction in stenosis to $50 \%$ or less as the main criterion for successful angioplasty, ${ }^{3}$ and this latter definition has also been used by other workers. ${ }^{4}$ The registry of the National Heart, Lung, and Blood Institute adopted the criterion of $20 \%$ reduction in stenosis, ${ }^{5}$ and other workers have followed this guideline.$^{67}$ Other definitions of primary success have, however, been reported, including a decrease in stenosis by $40 \%$ or greater, ${ }^{89}$ residual stenosis $\leqslant 40 \%,{ }^{10}$ and at least a $35 \%$ reduction in the initial percentage stenosis with post-angioplasty stenosis of $50 \%$ or less. ${ }^{11}$

One difficulty with the $20 \%$ reduction definition advocated by Gruentzig and coworkers is that the patient may be left with a residual stenosis of $70-80 \%$ and still be classified as a success. Sometimes this may be valid but in many patients residual exertional ischaemia would be expected, or recurrent symptoms associated with "restenosis" may be more likely. On the other hand, using criteria such as a residual stenosis of $<40 \%$ strictly would result in lower primary success rates and in a significant number of patients the procedure may erroneously be classified as unsuccessful, since in a patient with "subtotal" obstruction (so-called " $99 \%$ " or " $98 \%$ " stenosis) and unstable angina, reduction of the stenosis to $60 \%$ may result in a definite clinical success. The term "partial success" may be used to describe such a patient but this term has not really been used to any extent in published reports, presumably because mixtures of degrees of success are more difficult to handle statistically.

The term "partial success" may also relate to patients with multivessel disease in whom success may be achieved in one or more vessels but not in all. In these patients the term success refers to procedural success for the individual patient rather than to technical success of dilatation of an individual lesion. For example, in a patient with occlusion in one vessel and $90 \%$ stenosis in another, an attempt at reopening the occluded vessel may be unsuccessful whereas the dilatation of the stenosed vessel may be successful both angiographically and clinically, since in many cases treatment of the "culprit" or "target" lesion can result in clinical success without the need for "complete" revascularisation. ${ }^{12}$

Part of the problem of defining primary angiographic success is the inaccuracy inherent in the angiographic measurement of percentage diameter stenosis. This can be particularly difficult when there is intimal dissection. There is considerable interobserver and intraobserver variability in these measurements, ${ }^{13}$ and unless they are made blind by an independent observer, with or without computer assisted analysis, it is all too easy for any sort of angiographic improvement to be fitted to the given criteria for angiographic primary success. Even computer assisted calliper based techniques for analysis of data before and after angioplasty can be biased. Completely automated computer analysis systems may minimise this bias but these are not always practical for individual lesions. Such systems are reported to give lower estimates of stenosis than visual interpretation alone. ${ }^{1415}$ These difficulties make the precise definitions of angiographic success less useful and perhaps less valid than they might initially appear.

Although in some cases medical treatment may be considered the primary alternative, in most cases the true alternative is coronary artery bypass surgery. It may therefore be helpful to consider the success of angioplasty in the same terms as coronary artery bypass surgery. Defining primary success by a loose angiographic criterion such as any "angiographic improvement" or reduction in stenosis not associated with one of the major complications ${ }^{16}$ is rather like defining coronary artery bypass surgery as initially successful if the patient gets out of the operating room alive with bypass grafts in place. In a sense this is valid and many reports on coronary artery bypass surgery have focused on mortality rates. A similar loose and "unscientific" definition of primary success for angioplasty is often used in practice if not in print; and bearing in mind the difficulties inherent in the strict numerical angiographic definitions and the considerable variation in these definitions the less scientific interpretation may perhaps be more useful. Ideally, the definition of primary success should relate to the clinical circumstances and therefore to the goal in an individual patient. At one extreme, primary angiographic success in the setting of acute myocardial infarction may be simply defined as angiographic patency with prompt opacification of the distal vessel, ${ }^{17}$ whereas for stable angina pectoris with single vessel disease a residual angiographic stenosis of $\leqslant 50 \%$ may be regarded as a success because this would be expected to eliminate the symptoms. In many cases a less than ideal result could be regarded as a partial success.

Measurement of gradients across the lesions at the time of the procedure have also been used to 
evaluate the success of percutaneous transluminal coronary angioplasty. If the gradient is reduced to $<15 \mathrm{~mm} \mathrm{Hg}$ there is a better chance of long term success without the need for repeat angioplasty, ${ }^{18}$ and some workers have included a gradient criterion in their definition of primary success, that is a reduction to $15 \mathrm{~mm} \mathrm{Hg}^{11}$ or $10 \mathrm{~mm} \mathrm{Hg}$. ${ }^{4}$ This type of criterion is difficult to use clinically because there are technical difficulties with measurement with the balloon in position and with some balloon systems it is not possible to measure translesional gradient. In an individual patient it is hard to know what a high residual gradient means in terms of clinical success and in many cases attempting to reduce the gradient to a low level may be detrimental. This means that judgement and angiographic appearance have to be used in each case before proceeding to use a larger balloon, higher pressures, or longer inflation times. If a residual gradient of $<15 \mathrm{~mm} \mathrm{Hg}$ is used as a criterion for success ${ }^{11}$ a considerable number of patients with a higher residual gradient may still end up with a technically and clinically successful angioplasty. Certainly, restricting the term "success" to patients with a residual gradient of $<10 \mathrm{~mm} \mathrm{Hg}^{4}$ will unreasonably exclude many adequate procedures as primary successes. Coronary flow reserve has been used in a limited number of institutions to assess the results of angioplasty and to relate this to gradients, ${ }^{19}$ but this is really a research procedure and is unlikely to be clinically useful. It requires complex computer digital analysis which is not generally available.

\section{Clinical success}

"Secondary" or "clinical" success may be more important to the patient than primary angiographic success. Most patients who undergo coronary angioplasty have symptoms of angina or of acute myocardial ischaemia. Elimination of these symptoms, or at least a reduction to an acceptable level consistent with the patient's desired life style, would be a reasonable definition of clinical success. In some patients who manifest "silent ischaemia", however, the procedure may be undertaken primarily because of a positive stress test in the absence of clinically significant symptoms. Nevertheless, most of these patients will have had some symptoms or a cardiac event, such as subendocardial infarction, to warrant stress testing in the first place. Defining clinical success as a decrease in one anginal class ${ }^{11}$ may not be very realistic because a patient with class IV unstable angina may end up with class III angina on minor exertion and be classified as a success; and for most patients this would not be a reasonable improvement. This may, however, be considered a partial success, or even a complete success if the goal of the procedure were to "buy time" by stabilising a patient with multivessel disease before elective coronary bypass surgery. Nevertheless, standards for judging percutaneous transluminal coronary angioplasty should be as strict as those for bypass surgery. Decrease in anginal symptoms to grade II or less should be the minimum standard for success of angioplasty in most patients. If the criteria for clinical success are less strict than those for primary success the clinical success rate may be higher than the primary success rate, ${ }^{11}$ implying that primary "failures" become clinical successes. A primary "failure" should theoretically make a patient a candidate for alternative treatment, usually bypass surgery, but such a referral would not be appropriate if the primary "failure" is associated with clinical success.

Problems with the subjective definition of clinical success by classification of symptoms make objective evidence of myocardial ischaemia resulting from a coronary artery stenosis an important part of the assessment of the patient before and after percutaneous transluminal coronary angioplasty. Many patients have objective non-invasive stress studies before angioplasty that confirm the presence of myocardial ischaemia associated with symptoms of angina. In these patients a repeat stress test after the procedure showing negative results or an improvement to within acceptable levels would indicate clinical success. Several studies have shown improvement in stress tests with or without radionuclide multiple gated acquisition or thallium studies. ${ }^{1420}$ In some patients with unstable angina or preinfarction angina, relief of the unstable symptoms may be all that is required to establish clinical success, if this is the primary clinical goal of undertaking the procedure. In many of these cases an exercise test is not undertaken before the procedure because the symptoms are unstable. A subsequent positive exercise test with symptoms of stable exertional angina may still be consistent with the clinical success of the initial procedure, even if a second procedure is necessary to achieve further dilatation of the vessel or to dilate other vessels in a patient with multivessel disease. The optimal timing of such a post-angioplasty stress test has not been established. If it is too early the patient may not be able to exercise adequately because of groin discomfort. If it is done very late we may be seeing the effects of restenosis rather than those of inadequate initial dilatation. It is possible that some of the "restenosis" that is identified from positive stress tests after angioplasty is in fact inadequate initial dilatation. On the other hand, very early testing may not take into account possible "remoulding" of an artery after angioplasty, 
especially when there has been intimal dissection. Pacing stress tests immediately after angioplasty have been used to assess the effects of the procedure on coronary flow ${ }^{21}$ and we have used pacing combined with echocardiography or digital ventriculography in a few selected cases to document a functional improvement immediately after angioplasty. The value of such an early stress test in predicting subsequent progress remains to be determined and this type of test is unlikely to be widely applied. An exercise test performed at 2-3 weeks would avoid most of the difficulties.

When "primary" success is defined by angiographic criteria, "secondary" clinical success may be defined by symptomatic criteria which tend to be subjective, or by functional physiological criteria that take into account objective evidence of myocardial ischaemia, or by a combination of symptomatic and physiological criteria. The more objective assessment is particularly important in patients with "silent ischaemia" and in patients with "atypical" chest pain in whom some of the symptoms may not be cardiac in origin. If such objective functional criteria are used it may not be necessary to achieve complete absence of ischaemia, since an acceptable degree of improvement may indicate success. What is acceptable may vary with the clinical situation, the age of the patient, and other factors, but normally would exclude a stress test that is so strongly positive that it could indicate the likelihood of subsequent cardiac events such as myocardial infarction or sudden death. ${ }^{22-24}$

In patients with evolving acute myocardial infarction the clinical success of angioplasty should primarily be determined by the degree to which the damage done to the left ventricle is limited. This can be measured to some extent by evaluating by echocardiography or angiography the improvement in left ventricular function in the week or two after the infarction. Additionally, the degree to which spontaneous or stress induced postinfarction angina can be reduced or eliminated may be an important part of the clinical assessment of the success of an angioplasty procedure. ${ }^{25}$

\section{Long term success}

The long term success of an angioplasty procedure largely depends on the development of restenosis, which has been shown to occur in up to $35 \%$ of cases after a first procedure. This is a separate issue from primary success and initial clinical success. The rate of recurrence depends on several factors including the residual stenosis and the gradient at the end of the initial procedure, ${ }^{1826}$ but it also depends on the criteria by which restenosis is judged. Purely angio- graphic criteria such as stenosis of $\geqslant 50 \%$ at follow up angiography, ${ }^{426}$ or loss of $50 \%$ of the gain achieved at the initial angioplasty, ${ }^{61126}$ or increase of stenosis by $\geqslant 30 \%$ of the luminal diameter achieved after angioplasty ${ }^{6}$ suffer form the drawbacks of not being directly related to the functional state of the patient or the functional importance of the individual stenosis and also from difficulties with accurately measuring the diameter stenosis. Ideally, the term restenosis should only be applied when there is objective evidence of ischaemia by stress testing or other means-as with the initial angioplasty procedure. Analysis of important cardiac events such as myocardial infarction or bypass surgery may also be important in the assessment of long term results, ${ }^{27}$ particularly in multivessel disease. ${ }^{9111228}$ The completeness of revascularisation can have a considerable impact on follow up. ${ }^{9}$ After single vessel angioplasty of the "culprit" or "target" lesion some patients can maintain a long term clinical improvement despite multivessel disease and unstable angina. ${ }^{12}$

Coronary artery bypass surgery is usually the main alternative treatment to angioplasty and one important criterion of early and long term success may be the avoidance of such an operation. If dilatation does not sufficiently improve symptoms or if significant objective evidence of ischaemia remains the patient will require bypass surgery and angioplasty has clearly been a failure. On the other hand, if repeat angioplasty eliminates the symptoms and the objective evidence of ischaemia the initial procedure might be regarded as a partial success since the procedure as a whole has produced the desired effect. This type of analysis of the value of percutaneous transluminal coronary angioplasty as compared with coronary bypass surgery may be particularly important for multivessel disease. ${ }^{11}$ Until now there have been no valid randomised studies comparing angioplasty with bypass surgery, although such studies are clearly needed for an overall assessment of the value of angioplasty. The results of the multicentre study currently being set up for multivessel disease by the National Institutes of Health are eagerly awaited.

\section{References}

1 Gruentzig AR, Senning A, Siegenthaler WE. Nonoperative dilatation of coronary artery stenosis: percutaneous transluminal coronary angioplasty. $N$ Engl J Med 1979;301:61-8.

2 Anderson HV, Roubin GS, Leimgruber PP, Douglas JS, King SB, Gruentzig AR. Primary angiographic success rates of percutaneous transluminal coronary angioplasty. Am J Cardiol 1985;56:712-7.

3 Leimgruber PP, Roubin GS, Hollman J, et al. 
Restenosis after successful coronary angioplasty in patients with single-vessel disease. Circulation 1986; 73:710-7.

4 Sowton E, Timmis AD, Crick JCP, Griffin B, Yates AK, Deverall P. Early results after percutaneous transluminal coronary angioplasty in 400 patients. $\mathrm{Br}$ Heart $J$ 1986;56:115-20.

5 Kent KM, Bentivoglio LG, Block PC, et al. Percutaneous transluminal coronary angioplasty: report from the Registry of the National Heart, Lung, and Blood Institute. Am J Cardiol 1982;49:2011-20.

6 DiSciascio G, Vetrovec GW, Cowley MJ, Wolfgang TC. Early and late outcome of percutaneous transluminal coronary angioplasty for subacute and chronic total coronary occlusion. Am Heart J 1986; 111:833-9.

7 Cowley MJ, Vetrovec GW, DiSciascio G, Lewis SA, Hirsh PD, Wolfgang TC. Coronary angioplasty of multiple vessels: short-term outcome and long term results. Circulation 1985;6:1314-20.

8 Faxon DP, Kelsey SF, Ryan TJ, McCabe CH, Detre K. Determinants of successful percutaneous transluminal coronary angioplasty: report from the $\mathrm{Na}$ tional Heart, Lung, and Blood Institute Registry. Am Heart $J$ 1984;108:1019-23.

9 Mabin TA, Holmes DR Jr, Smith HC, et al. Follow-up clinical results in patients undergoing percutaneous transluminal coronary angioplasty. Circulation 1985; 71:754-60.

10 Hartzler GO, Rutherford BD, McConahay DR, et al. Percutaneous transluminal coronary angioplasty with and without thrombolytic therapy for treatment of acute myocardial infarction. Am Heart $J$ 1983;106: 965-73.

11 Myler RK, Topol EJ, Shaw RE, et al. Multiple vessel coronary angioplasty: classification, results and patterns of restenosis in 494 consecutive patients. Cathet Cardiovasc Diagn 1987;13:1-15.

12 Wohlgelernter D, Cleman M, Highman HA, Zaret BL. Percutaneous transluminal coronary angioplasty of the "culprit lesion" for management of unstable angina pectoris in patients with multivessel coronary artery disease. Am J Cardiol 1986;58:460-4.

13 Detre KM, Wright E, Murphy ML, Takaro T. Observer agreement in evaluating coronary angiograms. Circulation 1975;52:979-86.

14 Wijns W, Serruys PW, Simoons ML, et al. Predictive value of early maximal exercise test and thallium scintigraphy after successful percutaneous transluminal coronary angioplasty. Br Heart J 1985;53:194-200.

15 Gerbrands JJ, Reiber JHC, Booman F. Computer processing and classification of coronary occlusions. In: Gesema ES, Kanal LN, eds. Pattern recognition in practice. New York: North Holland, 1980:223.

16 Ilsley CDJ, Ablett MB. Percutaneous transluminal coronary angioplasty - results in patients with multiple coronary stenoses [Abstract]. Br Heart J 1985; 54:627-8.

17 O'Neill WW, Timmis GC, Bourdillon PD, et al. A prospective randomized clinical trial of intracoronary streptokinase versus coronary angioplasty for acute myocardial infarction. $N$ Engl J Med 1986;314:812-8.

18 Anderson MV, Roubin GS, Leimgruber PP, et al. Measurement of transtenotic pressure gradient during percutaneous transluminal coronary angioplasty. Circulation 1986;73:1223-30.

19 O'Neill WW, Walton J, Bates ER, et al. Criteria for successful coronary angioplasty as assessed by alterations in coronary vasodilatory reserve. $\mathrm{J} \mathrm{Am} \mathrm{Coll}$ Cardiol 1984;3:1382-90.

20 Rosing DR, van Raden MT, Mincemoyer RM, et al. Exercise, electrocardiographic and functional responses after percutaneous transluminal coronary angioplasty. Am J Cardiol 1984;53: 36C-41C.

21 Williams DO, Riley RS, Singh AK, Most AS. Coronary circulatory dynamics before and after successful coronary angioplasty. J Am Coll Cardiol 1983;1: 1268-72.

22 Ellestad MH, Wan MKC. Predictive implications of stress testing. Follow-up of 2700 subjects after maximum treadmill stress testing. Circulation 1975;51: 363.

23 McNeer JF, Margolis JR, Lee KL, et al. The role of the exercise test in the evaluation of patients for ischaemic heart disease. Circulation 1978;57:64-70.

24 DeBusk RF, Davidson DM, Houston N, Fitzgerald J. Serial ambulatory electrocardiography and treadmill exercise testing after uncomplicated myocardial infarction. Am J Cardiol 1980;45:547-54.

25 Fung AY, Lai P, Juni JE, et al. Prevention of subsequent exercise-induced preinfarct ischaemia by emergency coronary angioplasty in acute myocardial infarction: comparison with intracoronary streptokinase. J Am Coll Cardiol 1986;8:496-503.

26 Serruys PW, Geuskens R, de Feyter P, et al. Incidence of restenosis 30 and 60 days after successful PTCA: a quantitative coronary angiographic study in 200 consecutive patients [Abstract]. Circulation 1985; 72(suppl III):III-140.

27 Gruentzig AR, Schlumpf M, Siegenthaler W. Longterm results after coronary angioplasty [Abstract]. Circulation 1984;70(suppl II):II-323.

28 Cowley MJ, Vetrovec GW, DiSciascio G, Lewis SA, Hirsh PD, Wolfgang TC. Coronary angioplasty of multiple vessels: short term outcome and long term results. Circulation 1985;72:1314-20. 